\title{
Avaliação das dificuldades dos cuidadores em relação à higiene bucal de seus filhos com necessidades especiais
}

\section{Rafaela Rie Nishiyama*, Pedro Augusto Thiene Leme, Fábio Luiz Mialhe.}

\section{Resumo}

No presente estudo objetivou-se compreender as dificuldades e barreiras dos indivíduos com necessidades especiais e as estratégias de enfrentamento utilizadas para superar tais barreiras. Uma amostra aleatória de 30 cuidadores de pessoas com necessidades especiais foi convidada a participar deste estudo na instituição da APAE de São Pedro, na APAE de Piracicaba e no Centro de Reabilitação de Piracicaba. Os cuidadores responderam um questionário sociodemográfico e participaram de uma entrevista no qual foram gravadas e analisadas. Observou-se que a higiene bucal requer mais atenção do cirurgião-dentista para promover a melhor assistência à saúde bucal desses indivíduos.

\section{Palavras-chave:}

estratégias de enfrentamento, pessoas portadoras de necessidades especiais, saúde oral.

\section{Introdução}

Pacientes com necessidades especiais (PNE) possuem limitações que os tornam mais vulneráveis às doenças da cavidade bucal, tendo em vista que há uma série de fatores que dificultam essa questão como o fator formação dos cuidadores, que raras as ocasiões, inclui orientações sobre os cuidados que devem ser tomados, as complicações físicas provocadas pela doença base e o financeiro. Nesse contexto, observa-se que os cuidadores das pessoas com necessidades especiais precisam ter estratégias de enfrentamento quanto essas dificuldades para manter a saúde bucal do PNE. Tendo em vista o objetivo deste projeto foi compreender as dificuldades e barreiras dos responsáveis para o cuidado em saúde bucal de PNE.

\section{Resultados e Discussão}

Amostra: 30 cuidadores foram entrevistados. Todos eles eram do sexo feminino com idade variando entre 22 e 74 anos.

Coleta dos dados: A coleta de dados foi feita na sala de espera da APAE de Piracicaba, APAE de São Pedro e do Centro de Reabilitação. Os cuidadores com mais de 18 anos e principais responsáveis do indivíduo PNE foram convidados a participarem de uma entrevista na qual foi perguntado "Qual a maior dificuldade em fazer a higiene bucal do filho(a) (ou daquele que cuida)?" Após as entrevistas, foi aplicado um questionário sociodemográfico.

Analise dos dados: As entrevistas foram gravadas e analisadas por meio da técnica quantiqualitativa do Discurso do Sujeito Coletivo (Lefréve, 2013).

Pode-se observar no quadro 1 que os discursos individuais dos cuidadores que eram semelhantes foram agrupados em categorias de ideias centrais $A, B, C, D, E$ e F, na forma do Discurso do Sujeito Coletivo.

Quadro 1. Frequência das principais ideias centrais para a questão "Qual a maior dificuldade em fazer a higiene bucal do filho (ou daquele que cuida)?".

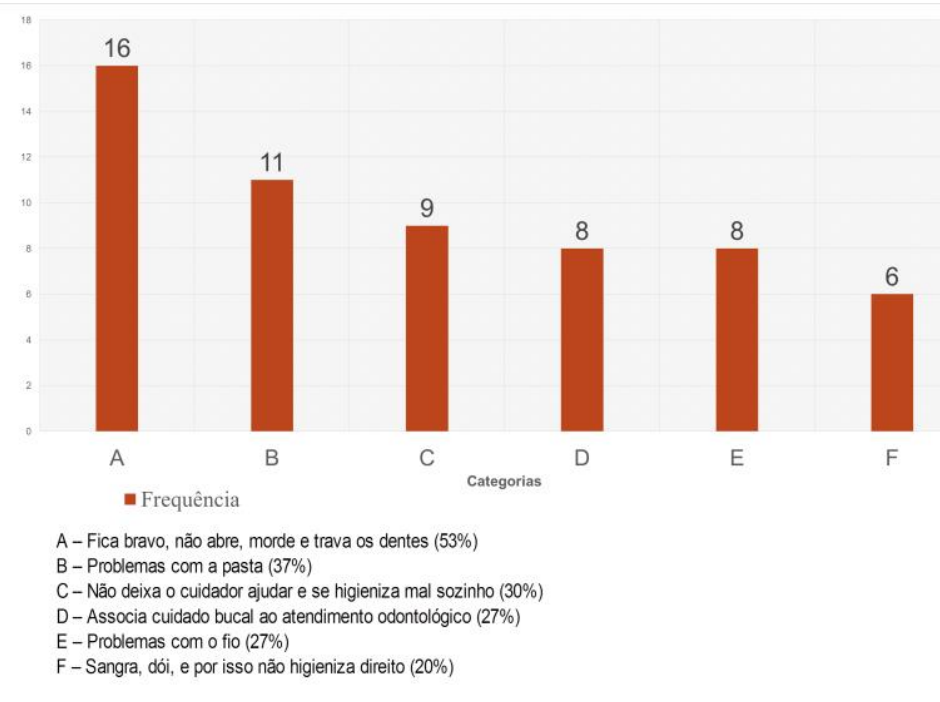

\section{Conclusões.}

Com o presente estudo, nota-se que uma quantidade considerável de cuidadores possui dificuldades em manter a saúde bucal do indivíduo PNE.

Por fim, conclui-se que a higiene bucal de indivíduos com necessidades especiais é uma questão complexa e requer mais atenção do cirurgião-dentista para promover a melhor assistência à saúde bucal desses indivíduos.

\section{Agradecimentos}

À Faculdade de Odontologia de Piracicaba, à Universidade Estatual de Campinas, à Pró-reitoria de Pesquisa da Unicamp, ao Programa Institucional de Bolsas de Iniciação Científica e as instituições APAE de São Pedro, APAE de Piracicaba e Centro de Reabilitação de Piracicaba meus sinceros agradecimentos.

Abanto $\mathrm{J}$ et al. Parental reports of the oral health-related quality of life of children with cerebral palsy. BMC Oral Health 2012; 12:15

Varellis MLZ. O Paciente com Necessidades Especiais na Odontologia. 3ed. São Paulo: Santos, 2016. 